\title{
Potential value of the calibrated automated thrombogram in patients after a cerebral venous sinus thrombosis; an exploratory study
}

Myrthe M. van der Bruggen ${ }^{1}$, Bram Kremers ${ }^{1,2}$, Rene van Oerle ${ }^{2,3}$, Robert J. van Oostenbrugge ${ }^{4}$ and Hugo ten Cate $^{1,2^{*}}$ (D)

\begin{abstract}
Background: Cerebral venous sinus thrombosis (CVST) is a relatively rare, but potentially lethal condition. In approximately $15 \%$ of the patients, the cause of CVST remains unclear. Conventional clotting tests such as prothrombin time and activated partial thromboplastin time are not sensitive enough to detect prothrombotic conditions nor mild haemostatic abnormalities. The calibrated automated thrombogram (CAT) is a physiological function test that might be able to detect minor aberrations in haemostasis. Therefore, we aimed to detect the presence of a prothrombotic state in patients who endured idiopathic CVST with the CAT assay.
\end{abstract}

Methods: Five adult patients with an idiopathic, radiologically proven CVST that had been admitted during the past 3 years were included in this study. The control group consisted of five age/gender matched healthy volunteers. Exclusion criteria were known haematological disorders, malignancy (current/past) or hormonal and anticoagulant therapy recipients. We obtained venous blood samples from all participants following cessation of anticoagulation. Using the CAT assay, we determined lag time, normalized endogenous thrombin potential (ETP), ETP reduction and normalized peak height. In addition, prothrombin concentrations were determined.

Results: We found no significant differences in lag time (4.7 min [4.5-4.9] vs $5.3 \mathrm{~min}[3.7-5.7], p=0.691$ ), normalized ETP (142\% [124-148] vs 124\% [88-138], $p=0.222$ ), ETP reduction (29\% [26-35] vs $28 \%$ [24-58], $p>0.999)$, and normalized peak height (155\% [153-175] vs 137 [94-154], $p=0.056$ ) between patients and their age/gender matched controls. In addition, prothrombin concentrations did not significantly differ between patients and controls (120\% [105-132] vs 127\% [87-139], $p>0.999)$.

Conclusion: Reasons for absent overt hypercoagulability within this study population may be the small patient sample, long time since the event (e.g. 3 years) and avoidance of acquired risk factors like oral contraception. Given the fact that CVST is a serious condition with a more than negligible risk of venous thrombosis event recurrence, exclusion of clinically relevant hypercoagulability remains a challenging topic to further study at the acute and later time points, particularly in patients with idiopathic CVST.

\footnotetext{
* Correspondence: h.tencate@maastrichtuniversity.nl

'Department of Internal Medicine, Maastricht University Medical Centre, Maastricht, the Netherlands

${ }^{2}$ Department of Biochemistry, Cardiovascular Research Institute Maastricht, Maastricht, the Netherlands

Full list of author information is available at the end of the article
}

(c) The Author(s). 2021 Open Access This article is licensed under a Creative Commons Attribution 4.0 International License, which permits use, sharing, adaptation, distribution and reproduction in any medium or format, as long as you give appropriate credit to the original author(s) and the source, provide a link to the Creative Commons licence, and indicate if changes were made. The images or other third party material in this article are included in the article's Creative Commons licence, unless indicated otherwise in a credit line to the material. If material is not included in the article's Creative Commons licence and your intended use is not permitted by statutory regulation or exceeds the permitted use, you will need to obtain permission directly from the copyright holder. To view a copy of this licence, visit http://creativecommons.org/licenses/by/4.0/ The Creative Commons Public Domain Dedication waiver (http://creativecommons.org/publicdomain/zero/1.0/) applies to the data made available in this article, unless otherwise stated in a credit line to the data. 


\section{Introduction}

Cerebral venous sinus thrombosis (CVST) is a relatively rare subtype of stroke. The incidence of this disease reported in the literature is approximately 3 per 100.000 per year, affecting more women than men [1,2]. Because of its rare occurrence the incidence of this disease might be underestimated, due to unawareness of its diagnosis. In addition, CVST is difficult to diagnose as it has a variable clinical presentation and may be challenging to confirm radiologically [3]. Complications include subarachnoid haemorrhage, cranial nerve palsy, epilepsy and transient ischemic attacks [4-6]. Taken together, the consequences of CVST can be severely incapacitating, and potentially life threatening [4]. This is illustrated by a case from a 19-year old female who visited the emergency room with acute headache in the last $24 \mathrm{~h}$. The pain was progressive, the patient experienced nausea and vertigo, and she had vomited several times. In addition, she was both phono- and photophobic. Her medical history did not show any peculiarities and the family history was negative for thrombotic diseases. She did not suffer head trauma or infections, nor did she use any hormonal/contraceptive therapy. Magnetic resonance imaging showed a thrombosis of the jugular vein, sigmoid sinus, right transverse sinus and the distal part of the sagittal sinus. Thrombophilia analysis did not show any of the common traits including factor $V$ Leiden, prothrombin 20210 or inhibitor deficiencies. Despite adequate treatment with anticoagulants, the patient still regularly experienced loss of vision and headache years after the event. This case illustrates how severe CVST can influence a (young) patient's life.

Recent occurrences of CVST in the setting of Covid19 vaccination, triggered interest for this disorder [7]. There are several risk factors that contribute to the development of CVST. Examples are prothrombotic conditions such as protein $\mathrm{C}$-, protein $\mathrm{S}$-, and antithrombin deficiency. Furthermore, tumours, haematological disorders and the use of oral hormonal contraception are associated with CVST $[1,8,9]$. The risk factors that contribute to the development of CVST can be identified in most patients. However, in approximately $15-20 \%$ of patients no cause or risk factor is identified $[1,10]$. Subsequently, monitoring this patient group and estimating the risk for recurrence is rather difficult [11].

In general, hypercoagulability is a key element in venous thrombosis and in addition to the mentioned thrombophilic traits, acquired factors like oral contraceptives have an important impact on coagulation through an acquired resistance against activated protein $C$ [12]. The intrinsic coagulation properties can be assessed through the calibrated automated thrombogram (CAT). The CAT, developed by Hemker and coworkers, is a semi-automated thrombin generation technique, which provides the ability to monitor thrombin concentrations in time, as the substrate for thrombin is fluorescently labeled [13, 14]. The CAT method is currently well-accepted as a research tool and has proven to be useful in several different domains such as platelet-plasma interactions, detection and quantification of thrombotic/bleeding tendency, and control of pro-coagulant and antithrombotic therapy $[12,15-17]$. During a curiosity driven exploration of the CAT data in consecutive patients referred to the vascular outpatient clinic, we observed three patients who suffered from idiopathic CVST and had substantial elevations in thrombin generation (i.e. mean endogenous thrombin potential (ETP) 190\%, mean normalized peak 352\%) without any reasonable explanation.

Based on this unpublished observation we designed the present study to investigate whether abnormal CAT responses would indeed be a consistent finding in patients who suffered a CVST.

\section{Methods}

Adult patients who endured CVST without known cause or risk factors were included in this patient study. We searched hospital records for CVST patients between January 1st 2012 and May 24th 2017 using the Dutch financial coding system for hospital care (DBC-codes). There is no specific code for CVST or for cerebral venous thrombosis. Therefore, all records of patients assigned to the code "ischemic stroke", "haemorrhagic stroke", "headache" and "not other specified" were screened. Based on this search strategy we identified 29 CVST patients. Next, patients under 18 years of age, patients with known coagulation disorders, malignancy (in the past), using hormonal contraception or other hormonal therapy, or anticoagulants and patients who are mentally disabled, were excluded from this study.

Blood plasma from healthy age and gender matched volunteers was used as reference material. Healthy volunteers were recruited through advertisements at the faculty of health, medicine and life sciences at Maastricht University. The same exclusion criteria as with patients applied.

All subjects who were eligible for inclusion in this study underwent a venepuncture and filled in a questionnaire with regard to thrombotic risk factors. This was done to place outcome measures in a clinical perspective.

All subjects were informed and provided written consent.

The study was performed at Maastricht University Medical Centre (MUMC+) and approved by the local medical ethical committee (Medical ethical committee MUMC, approval number; NL 63775.068.17). 


\section{Blood collection and storage}

Four $9 \mathrm{~mL}$ tubes with $3.2 \%$ trisodium citrate were collected through antecubital venipuncture. The blood was processed to platelet poor plasma (PPP) within $1 \mathrm{~h}$ after collection via previously described methods [18, 19]. PPP was stored at $-80{ }^{\circ} \mathrm{C}$ until analysis [20]. All samples were analyzed at one time point to prevent repeated freeze-thaw cycles. Plasma from healthy volunteers was processed and stored in the same manner, with the same number of freeze-thaw cycles as plasma from patients.

\section{Markers of coagulation Thrombin generation}

The coagulation potential in plasma was assessed using the CAT assay (Thrombinoscope BV, Maastricht, the Netherlands). Within this method, low-affinity fluorogenic substrate for thrombin (Z-Gly-Gly-Arg-AMC; Bachem, Bubendorf, Switzerland) is added to allow continuous monitoring of thrombin formation. For each measurement, $80 \mu \mathrm{L}$ of human PPP was added to $20 \mu \mathrm{L}$ of fluorogenic substrate, $20 \mu \mathrm{L}$ of trigger reagent and calcium chloride, as previous reported $[19,21]$. The CAT assay was performed with and without the presence of soluble thrombomodulin (TM; Asahi Kasei Pharma Corporation, Tagata, Japan), to enable protein $\mathrm{C}$ depend testing [12]. TG curves were calculated using Thrombinoscope software (Thrombinoscope, Maastricht, The Netherlands). Analysis resulted in four main outcome parameters: 1 . Lag time; the time until clotting occurs. 2. ETP; the total amount of thrombin formed during the measurement, i.e. the area under the curve. 3. Peak height; maximum amount of thrombin generation. 4 . Peak reduction; time needed for clot degradation [19].

\section{Prothrombin levels}

Being an important determinant of the CAT, prothrombin was measured with a one stage FII assay on a Siemens BCSxp instrument according to the manufacturer's instructions.

\section{Statistical analysis}

Baseline characteristics were collected and tabulated. Differences in thrombin generation outcome measures between patients and controls were analyzed using the Mann-Whitney $U$ test (nonparametric) because of the small sample size. Results are shown as the median and 25th-75th percentile.

$P$-values $<0.05$ were considered statistically significant. All analyses were performed using GraphPad Prism version 7 for Windows, GraphPad Software, La Jolla California USA, www.graphpad.com.

\section{Results}

Baseline characteristics

Eleven patients were eligible for participation in the study. Four patients were not interested in participating. From the remaining seven patients, one patient did not appear at the appointment and one patient used anticoagulant drugs despite the screening efforts. Consequently, 5 patients and 5 controls were enrolled in the study. A flow-chart of the inclusion- and exclusion process can be found in Fig. 1.

At the time of the event, there was no relevant medical history or use of medication that was expected to provoke CVST. Medical history of the five patients at the time of the event included: polyarticular juvenile idiopathic arthritis (1 patient), exertional headaches ( 1 patient), and hypertension (1 patient). Medication use included TNF- $\alpha$ blocker (1 patient), metoprolol (1 patient), ibuprofen and paracetamol (1 patient). Patient characteristics of all study participants at the time of inclusion are shown in Table 1. No differences in key risk factors and relevant medication between patients and controls were observed.

\section{Markers of coagulation \\ 1.1 No significant differences in thrombin generation were observed}

The CAT thrombin generation assay was performed and lag time, ETP, ETP reduction and peak height were assessed [Table 2]. There was no significant difference in lag time between patients and controls $(p=0.691)$ [Fig. 2A]. Although normalized peak height and ETP were both higher in patients than controls, neither difference was statistically significant $(p=0.056, p=0.222$ respectively) (Table 2 and Fig. 2B/C). ETP reduction, which is the difference in ETP determined with and without presence of TM, was similar between the groups [Table 2 and Fig. 2D].

\subsection{No significant differences in prothrombin concentration were observed}

Prothrombin was tested as it is known to be a main determinant of peak height and ETP [22-24]. No significant difference in prothrombin concentration was observed [Table 2/Fig. 2E].

\section{Discussion}

The present study assessed the presence of unexplained hypercoagulability in patients well beyond the acute phase of a CVST. We analysed thrombin generation by CAT based on a previous finding of elevated TG levels in 3 patients with CVST seen at the outpatient clinic. Two of the original 3 patients were included in the present study, the third patient was on rivaroxaban and could for that reason not be studied. 


\section{1 no CVST}

\section{Records screened}

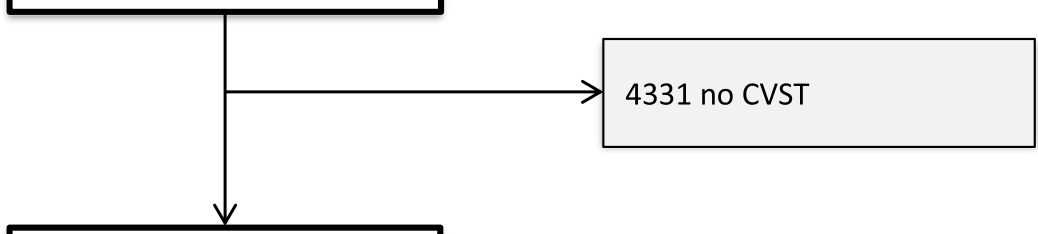

29 CVST patients identified

18 patients excluded:

4x Not radiologically proven

$5 x$ Known coagulation disorder

$1 x$ Septic infection

1x Non-Dutch/living abroad

$1 x$ Under 18 years of age

$3 x$ Malignancy

11 CVST patients eligible for

$3 x$ Incapacitated/disabled

\section{inclusion}

4 non responders

\section{the study}

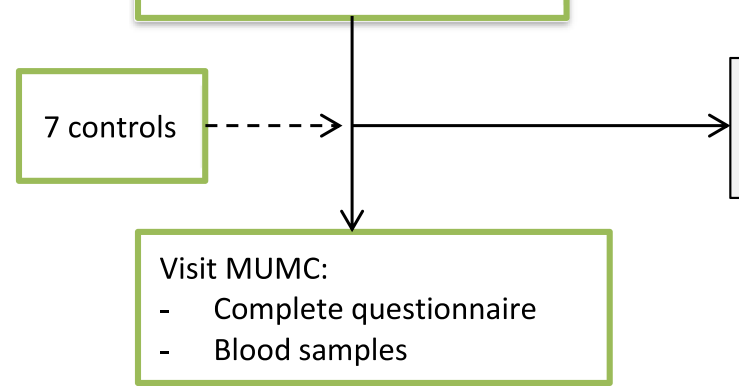

2 patients excluded:

$1 x$ no show

$1 \mathrm{x}$ patient used anticoagulants

Fig. 1 Flowchart inclusion. CVST = Cerebral venous sinus thrombosis. MUMC = Maastricht University Medical Centre

Table 1 Baseline characteristics

\begin{tabular}{lll}
\hline & Patients & Controls \\
\hline Female gender (\%) & $100 \%$ & $100 \%$ \\
Age in years (mean) & $42( \pm 12)$ & $46( \pm 13)$ \\
Years after event (mean) & 2,5 & \\
Antiplatelet medication & 0 & 0 \\
Anti-inflammatory drugs & 0 & 1 \\
Alcohol consumption (U/week) & 1 & 2 \\
Smoking & 0 & 0 \\
\hline
\end{tabular}

Thrombin generation via the CAT method was performed in order to assess hypercoagulability. The first outcome parameter we considered was lag time. As expected, lag time did not significantly differ between patients and controls, as idiopathic hypercoagulability is mainly reflected by an increase in ETP and peak height $[23,25]$.

Subsequently we determined ETP, ETP reduction and peak height. ETP did not significantly differ between patients and controls. We tested ETP reduction by adding TM. Binding of thrombin to TM activates Protein C, a potent anticoagulant factor $[13,26]$. We did not observe a significant difference in ETP reduction. 
Table 2 Thrombin generation outcome measures shown as median [25-75 percentiles]. No significant differences were observed. $\mathrm{ETP}=$ endogenous thrombin potential

\begin{tabular}{llll}
\hline & Patients & Controls & $P$-value \\
\hline Lag time (min) & $4.7[4.5-4.9]$ & $5.3[3.7-5.7]$ & 0.691 \\
Normalized ETP (\%) & $142[124-148]$ & $124[88-138]$ & 0.222 \\
ETP reduction (\%) & $29[26-35]$ & $28[24-58]$ & $>0.999$ \\
Normalized Peak Height (\%) & $155[153-175]$ & $137.4[94-154]$ & 0.056 \\
Prothrombin concentration (\%) & $120[105-132]$ & $127[87-139]$ & $>0.999$ \\
\hline
\end{tabular}
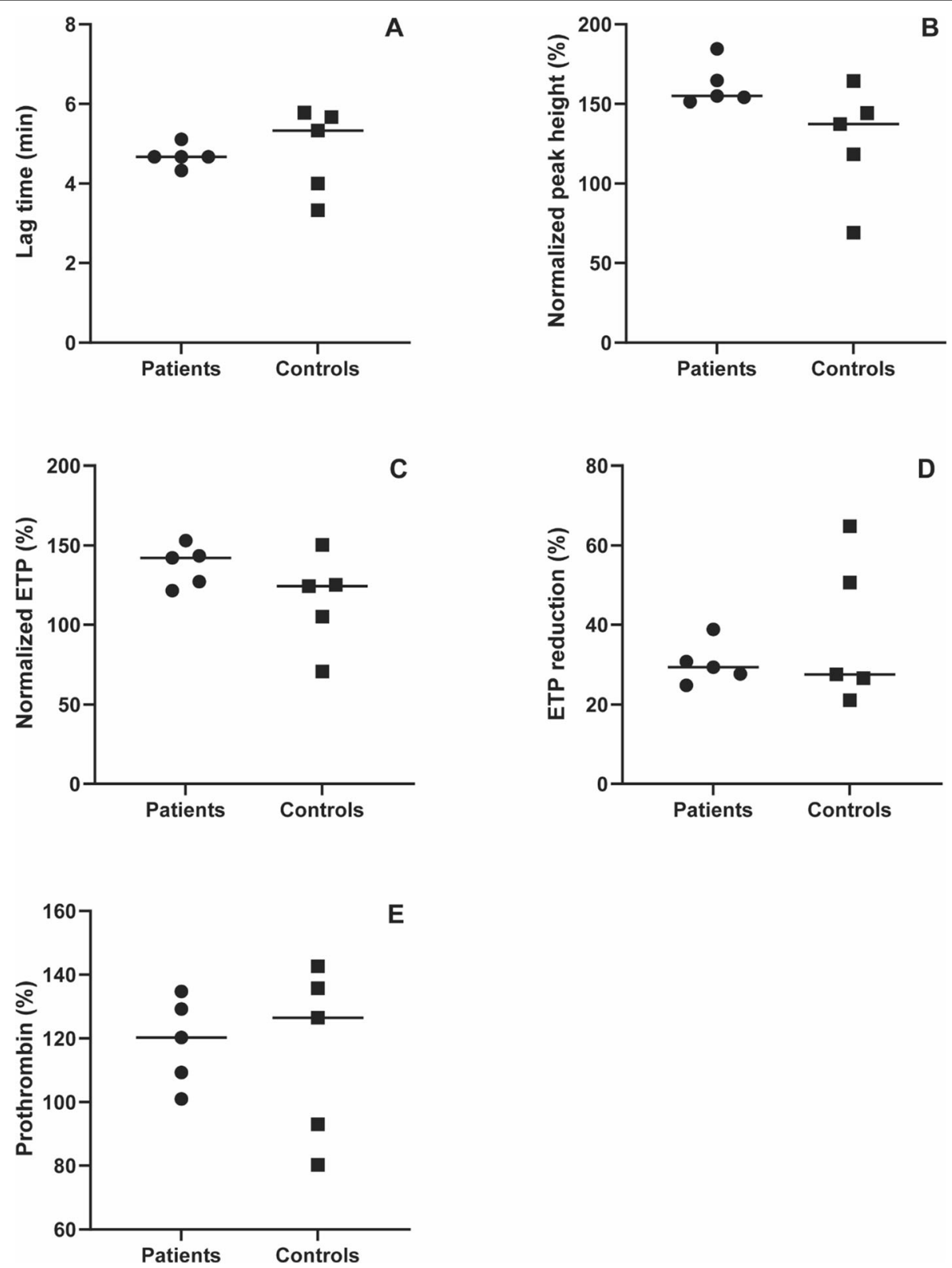

Fig. 2 Thrombin generation and prothrombin measurements in cerebral venous sinus thrombosis (CVST) patients and healthy controls. (A) Lag time (B) Normalized peak height. (C) Normalized endogenous thrombin potential (ETP). (D) ETP reduction (E) Prothrombin concentration 
In addition, peak height of the thrombin generation curve was determined. Although there is a visual difference between the two groups (Fig. 2B), this did not reach statistical significance, probably due to the small sample size.

Based on a previous study which showed increased ETP and peak height in patients after deep venous thrombosis up till 2 years after the event [24], we expected to detect a similar difference in our study population. Other studies do support the findings of increased ETP and peak height after a thrombotic event [24]. The clinical relevance would be found in the ability to predict recurrent thrombotic events. However, results regarding the predictive value of the thrombin generation assay on development of a secondary event (venous thrombotic event) vary widely [20, 27-31]. It should be mentioned that some studies used whole blood, others used PPP or platelet rich plasma, which makes it difficult to compare the outcomes. Nevertheless, we can conclude that the role of thrombin generation as a predictor is still uncertain.

Patients with a first episode of CVST, a potentially devastating condition, are usually treated with anticoagulation for a limited time period, ranging from 3 to 6 months. This time is defined, considering the risk of recurrent disease after cessation of anticoagulation as low. However, this risk is not negligible and incidences ranging from 3 to $18 \%$ - depending on the risk factors for development of recurrence CVST and/or other venous thrombotic events (VTE) have been reported [1, 10, 11]. Literature suggests that the risk of recurrence is highest up till one till 2 year(s) after the event $[11,32]$. Therefore, characterizing thrombosis risk after stopping anticoagulation may be useful.

In all patients with CVST, avoidable risk factors like oral contraceptives are typically recorded and eliminated, whereas in younger individual's variable thrombophilia screening is done. Since thrombin generation might have been a convenient single test for detecting thrombophilia, we focused on its use in this population.

\section{Study limitations}

Limitations of this study include the small number of participants remaining after an extensive search and selection process. CVST is a relatively rare disease and we selected an even smaller group by only including idiopathic CVST patients. The direction of some of the TG comparisons showed a trend towards hypercoagulability in the patients and it may be assumed that in a larger population true differences may emerge. Furthermore, we excluded patients with a severe course of the disease, as we excluded disabled/incapacitated subjects. This might have led to selection bias in the current population. Finally, the time after the event might be too long to be able to detect hypercoagulability and in case of risk factors like oral contraceptives, these were eliminated after the first event. We included patients after 3 years on average. It might simply be that the hypercoagulable state tends to normalize after this time interval.

\section{Conclusions}

In this pilot study we did not find any significant aberration in haemostasis between patients that suffered from CVST in the past, and age/gender machted controls. This is potentially due to a small sample size and relatively long follow-up time. Given the fact that CVST is a serious condition with a more than negligible risk of (VTE) recurrence, exclusion of clinically relevant hypercoagulability remains a challenging topic to further study at the acute and later time points, particularly in patients with idiopathic CVST.

\section{Abbreviations}

CAT: Calibrated automated thrombogram; CVST: Cerebral venous sinus thrombosis; DBC: Diagnosis-treatment combinations; ETP: Endogenous thrombin potential; MUMC: Maastricht university medical centre; PPP: Platelet poor plasma; TM: Thrombomodulin; VTE: Venous thrombotic event

\section{Acknowledgements \\ Not applicable.}

\section{Authors' contributions}

$M B, R O, R J O$, and $H T$ conceived and designed the study. $M B, B K$ and $R O$ performed the measurements. $\mathrm{MB}, \mathrm{RO}$ and $\mathrm{HT}$ analysed the data and interpreted the results. $\mathrm{MB}$ drafted the work. $\mathrm{MB}, \mathrm{BK}, \mathrm{RO}, \mathrm{RJO}$, and $\mathrm{HT}$ critically edited and revised the manuscript. $M B, B K, R O, R J O$, and $H T$ have approved the final version of the manuscript and agree to be accountable for their contributions.

Authors' information

Not applicable.

\section{Funding}

No specific funding was obtained for this study.

Availability of data and materials

The datasets used and/or analysed during the current study are available from the corresponding author on reasonable request.

\section{Declarations}

Ethics approval and consent to participate

The study was performed at the MUMC and approved by the local medical ethical committee (Medical ethical committee MUMC, approval number; NL 63775.068.17 All participants gave written informed consent.

\section{Consent for publication}

Not applicable.

\section{Competing interests}

The authors declare that they have no competing interests.

\section{Author details}

${ }^{1}$ Department of Internal Medicine, Maastricht University Medical Centre, Maastricht, the Netherlands. '2Department of Biochemistry, Cardiovascular Research Institute Maastricht, Maastricht, the Netherlands. ${ }^{3}$ Clinical Diagnostic Laboratory, Maastricht University Medical Center, Maastricht, the Netherlands. ${ }^{4}$ Department of Neurology, Maastricht University Medical Centre, Maastricht, the Netherlands. 
Received: 28 July 2021 Accepted: 21 October 2021

Published online: 04 November 2021

\section{References}

1. Weimar C. Diagnosis and treatment of cerebral venous and sinus thrombosis. Curr Neurol Neurosci Rep. 2014;14(1):417.

2. Silvis SM, de Sousa DA, Ferro JM, Coutinho JM. Cerebral venous thrombosis. Nat Rev Neurol. 2017;13(9):555-65.

3. Gao L, Xu W, Li T, Yu X, Cao S, Xu H, et al. Accuracy of magnetic resonance venography in diagnosing cerebral venous sinus thrombosis. Thromb Res. 2018;167:64-73.

4. Ferro JM, Canhao P, Stam J, Bousser MG, Barinagarrementeria F, Investigators I. Prognosis of cerebral vein and dural sinus thrombosis: results of the international study on cerebral vein and Dural sinus thrombosis (ISCV T). Stroke. 2004:35(3):664-70.

5. Breteau G, Mounier-Vehier F, Godefroy O, Gauvrit JY, Mackowiak-Cordoliani MA, Girot M, et al. Cerebral venous thrombosis 3-year clinical outcome in 55 consecutive patients. J Neurol. 2003;250(1):29-35.

6. Gameiro J, Ferro JM, Canhao P, Stam J, Barinagarrementeria F, Lindgren A, et al. Prognosis of cerebral vein thrombosis presenting as isolated headache: early vs. late diagnosis. Cephalalgia. 2012;32(5):407-12.

7. Franchini M, Liumbruno GM, Pezzo M. COVID-19 vaccine-associated immune thrombosis and thrombocytopenia (VITT): Diagnostic and therapeutic recommendations for a new syndrome. Eur J Haematol. n/a(n/a).

8. Dentali F, Crowther M, Ageno W. Thrombophilic abnormalities, oral contraceptives, and risk of cerebral vein thrombosis: a meta-analysis. Blood. 2006;107(7):2766-73

9. Luo $Y$, Tian $X$, Wang $X$. Diagnosis and treatment of cerebral venous sinus thrombosis: a review. Front Aging Neurosci. 2018;10:2.

10. Coutinho JM, Stam J. How to treat cerebral venous and sinus thrombosis. J Thromb Haemost. 2010;8(5):877-83

11. Palazzo $P$, Agius $P$, Ingrand $P$, Ciron J, Lamy M, Berthomet $A$, et al. Venous thrombotic recurrence after cerebral venous thrombosis: a long-term follow-up study. Stroke. 2017:48(2):321-6.

12. Dielis AWJHCE, Spronk HMH, van Oerle R, Hamulya'k K, Cate t, Rosing J. Coagulation factors and the protein $C$ system as determinants of thrombin generation in a normal population. Thromb Haemost. 2008;6(1):125-31.

13. Duarte RCF, Ferreira CN, Rios DRA, Reis HJD, Carvalho MDG. Thrombin generation assays for global evaluation of the hemostatic system: perspectives and limitations. Rev Bras Hematol Hemoter. 2017;39(3):259-65.

14. Hemker HC, Giesen P. AR, Regnault V, de Smed E, Lecompte T, Béguin S. the calibrated automated Thrombogram (CAT) a universal routine test for hyper- and hypocoagulability. Pathophysiol Haemost Thromb. 2002;32(5-6): 249-53.

15. Bloemen S, Zwaveling S, Ten Cate H, Ten Cate-Hoek A, de Laat B. Prediction of bleeding risk in patients taking vitamin $\mathrm{K}$ antagonists using thrombin generation testing. PLoS One. 2017;12(5):e0176967.

16. Hemker HC, Al Dieri R, Beguin S. Thrombin generation assays: accruing clinical relevance. Curr Opin Hematol. 2004;11(3):170-5.

17. Ten Cate H. Thrombin generation in clinical conditions. Thromb Res. 2012; 129(3):367-70

18. Loeffen R, Kleinegris MC, Loubele ST, Pluijmen PH, Fens D, van Oerle R, et al. Preanalytic variables of thrombin generation: towards a standard procedure and validation of the method. J Thromb Haemost. 2012;10(12):2544-54.

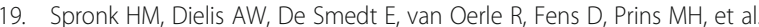
Assessment of thrombin generation II: validation of the calibrated automated Thrombogram in platelet-poor plasma in a clinical laboratory. Thromb Haemost. 2008;100(2):362-4.

20. Wexels F, Dahl OE, Pripp AH, Seljeflot I. Thrombin generation in patients with suspected venous thromboembolism. Clin Appl Thromb Hemost. 2017; 23(5):416-21.

21. Kremers BMM, Birocchi $S$, van Oerle $R$, Zeerleder $S$, Spronk HMH, Mees BME, et al. Searching for a Common Thrombo-Inflammatory Basis in Patients With Deep Vein Thrombosis or Peripheral Artery Disease. Front Cardiovasc Med. 2019;6(33)

22. Butenas S, van't Veer C, Mann KG. "Normal" thrombin generation. Blood. 1999;94(7):2169-78.

23. Hemker HC, Beguin S. Thrombin generation in plasma: its assessment via the endogenous thrombin potential. Thromb Haemost. 1995;74(1):134-8.
24. ten Cate-Hoek AJ, Dielis AW, Spronk HM, van Oerle R, Hamulyak K, Prins MH, et al. Thrombin generation in patients after acute deep-vein thrombosis. Thromb Haemost. 2008;100(2):240-5.

25. Lutsey PL, Folsom AR, Heckbert SR, Cushman M. Peak thrombin generation and subsequent venous thromboembolism: the longitudinal investigation of thromboembolism etiology (LITE) study. Thromb Haemost. 2009;7(10): 1639-48.

26. Machlus KR, Colby EA, Wu JR, Koch GG, Key NS, Wolberg AS. Effects of tissue factor, thrombomodulin and elevated clotting factor levels on thrombin generation in the calibrated automated thrombogram. Thromb Haemost. 2009:102(5):936-44.

27. Joly BS, Sudrie-Arnaud B, Barbay V, Borg JY, Le Cam Duchez V. Thrombin generation test as a marker for high risk venous thrombosis pregnancies. Thromb Thrombolysis. 2018;45(1):114-21.

28. Park MS, Spears GM, Bailey KR, Xue A, Ferrara MJ, Headlee A, et al. Thrombin generation profiles as predictors of symptomatic venous thromboembolism after trauma: a prospective cohort study. J Trauma Acute Care Surg. 2017; 83(3):381-7.

29. Riva N, Vella K, Hickey K, Bertu L, Zammit D, Spiteri S, et al. Biomarkers for the diagnosis of venous thromboembolism: D-dimer, thrombin generation, procoagulant phospholipid and soluble P-selectin. J Clin Pathol. 2018;71(11): 1015-22.

30. Voils SA, Lemon SJ, Jordan J, Riley P, Frye R. Early thrombin formation capacity in trauma patients and association with venous thromboembolism. Thromb Res. 2016;147:13-5.

31. Lippi G, Danese E, Favaloro EJ, Montagnana M, Franchini M. Diagnostics in venous thromboembolism: from origin to future prospects. Semin Thromb Hemost. 2015:41(4):374-81.

32. Miranda B, Ferro JM, Canhao P, Stam J, Bousser MG, Barinagarrementeria F, et al. Venous thromboembolic events after cerebral vein thrombosis. Stroke. 2010:41(9):1901-6.

\section{Publisher's Note}

Springer Nature remains neutral with regard to jurisdictional claims in published maps and institutional affiliations.

Ready to submit your research? Choose BMC and benefit from:

- fast, convenient online submission

- thorough peer review by experienced researchers in your field

- rapid publication on acceptance

- support for research data, including large and complex data types

- gold Open Access which fosters wider collaboration and increased citations

- maximum visibility for your research: over $100 \mathrm{M}$ website views per year

At BMC, research is always in progress.

Learn more biomedcentral.com/submissions 